\title{
CHEMISTRY
}

\section{IONITES ON THE BASIS OF CLINOPTILOLITE}

\author{
Professor, Doctor Givi Papava, \\ Doctor Marina Gurgenishvili, \\ Doctor Ia Chitrekashvili, \\ Doctor Eter Gavashelidze, \\ Doctor Gelashvili Nazi
}

Georgia, Tbilisi, Petre Melikishvili Institute of Physical and Organic Chemistry of Ivane Javakhishvili Tbilisi State University

DOI: https://doi.org/10.31435/rsglobal_wos/31102019/6740

\section{ARTICLE INFO}

Received: 12 August 2019

Accepted: 19 October 2019

Published: 31 October 2019

\section{KEYWORDS}

Ionite,

ionogen group,

zeolite,

clinoptillolite,

cationite,

polymerization.

\begin{abstract}
Organomineral ionites have been synthesized, in which natural mineral sorbent is chemically bound to organic part of a molecsule, containing ionogen groups. Ionogen groups of these ionites contribute to efficient exchange in water solutions. They might be used for cleaning drainage waters and technical solutions, as well as for purification of medicinal preparations from various admixes. Hydrogen forms of natural zeolite clinoptilolite and bromoacetic acid were used to resolve this problem. Chemical modification of clinoptilolite, by inculcation of ionogen groups into zeolite skeleton, enables us to increase significantly ionite exchange capacity. Static exchange capacity of a cationite with carboxyl ionogen groups increases from $0,1-0,9$ (for chemically unmodified zeolite) to 5 - $6 \mathrm{mg}$.equiv./g.
\end{abstract}

Citation: Givi Papava, Marina Gurgenishvili, Ia Chitrekashvili, Eter Gavashelidze, Gelashvili Nazi. (2019) Ionites on the Basis of Clinoptilolite. International Academy Journal Web of Scholar. 10(40), doi: 10.31435/rsglobal_wos/31102019/6740

Copyright: (C) 2019 Givi Papava, Marina Gurgenishvili, Ia Chitrekashvili, Eter Gavashelidze, Gelashvili Nazi. This is an open-access article distributed under the terms of the Creative Commons Attribution License (CC BY). The use, distribution or reproduction in other forums is permitted, provided the original author(s) or licensor are credited and that the original publication in this journal is cited, in accordance with accepted academic practice. No use, distribution or reproduction is permitted which does not comply with these terms.

Introduction. Organic monomers with double links, containing ionogen groups were used to synthesize ionites. Ionites were polymerized, as a result of which organic ionites were obtained with ionogen groups in elementary rings of polymers characterized by spatial structure.

At the application of inorganic natural sorbents, for example zeolites in ionite synthesis, zeolite is presented just as a matrix, playing a role of a skeleton of synthetic organic ionite [1 - 3].

It was considered interesting to synthesize organomineral ionites, in which natural mineral sorbent would be chemically bound to organic part of a molecule, containing ionogen groups.

In the work [2] zeolite was modified through its treatment in acetoacetic acid. In that method of ionite synthesis, ionogen groups were not introduced into zeolite skeleton, capable to participate in ion exchange process. As a result of such treatment zeolite exchange capacity fell from 0,9 to $0,3 \mathrm{mg}$-equiv/g.

The present work pursued to synthesize ionites in which organic molecule, containing ionogen groups, would be chemically bound to zeolite skeleton.

Ionogen group of such ionites is capable to contribute to efficient exchange in water solutions and they might be used for treatment of drainage waters, and technical solutions as well as for purification of medicinal preparations from various admixes.

Experimental part.

Materials. For the resolution of this problem the authors of the present work used natural zeolite - clinoptilolite of the following composition, expressed in oxides: 


\section{$\left(\mathrm{Na}_{2} \mathrm{~K}_{2}\right) \mathrm{O} \cdot \mathrm{Al}_{2} \mathrm{O}_{3} \cdot 10 \mathrm{SiO}_{2} \cdot 8 \mathrm{H}_{2} \mathrm{O}$.}

The other component was bromoacetic acid $\left(\mathrm{BrCH}_{2} \mathrm{COOH}\right)$, which due to increased activity of bromine atom easily comes into reaction with hydrogen atom of $\mathrm{H}$-form zeolite.

Zeolite easily absorbs bromoacetic acid, but bromoacetic acid molecules are washed out easily from zeolite pores too. Preliminary experiments proved that at the treatment by water, bromoacetic acid is washed out completely.

Technics. Initially zeolite was treated by $5 \%$ hydrochloric acid solution. In this way it is transformed into hydrogen form ( $\mathrm{H}$-form zeolite). At this moment cations, mainly $\mathrm{K}$ and $\mathrm{Na}$, were substituted by hydrogen atoms. After thorough washing it was dried to remove water. At the interaction of bromoacetic acid and $\mathrm{H}$-form zeolite, in organic solvent, at the temperature $60-80^{\circ} \mathrm{C}$, we obtained ionite with carboxyl ionogen groups. Schematically the reaction can be presented as follows:

$$
\begin{gathered}
\mathrm{Z}-\mathrm{Na}(\mathrm{K})+\mathrm{HCI} \rightarrow \mathrm{Z}-\mathrm{H}+\mathrm{Na}(\mathrm{K}) \mathrm{CI} \\
\mathrm{Z}-\mathrm{H}+\mathrm{BrCH}_{2} \mathrm{COOH} \rightarrow \mathrm{Z}-\mathrm{CH}_{2} \mathrm{COOH}+\mathrm{HBr}
\end{gathered}
$$

IR-spectral studies of ionites showed absorption bands in the area $1090-1050 \mathrm{~cm}^{-1}$, inherent to $\mathrm{Si}-\mathrm{O}-\mathrm{C}$ chemical bond, referring to the fact that the remainder of acetic acid is chemically bound to zeolite skeleton. Reiterated washing by water showed that nature and intensity of absorption bands doesn't change, which refers to the presence of $\mathrm{Si}-\mathrm{O}-\mathrm{C}$ chemical bond.

Cationite on the basis of modified natural zeolite - clinoptilolite and bromoacetic acid was obtained as follows: natural zeolite-clinoptilolite was crushed into particles of $1-2 \mathrm{~mm}$, than $0,5 \mathrm{~N}$ hydrochloric acid solution was added to it and the mix was heated for 4-5 hours. Then it was decanted many times till it showed negative reaction to chlorine atom, and finally, it was dried at $120^{\circ} \mathrm{C}$.

$\mathrm{H}$-form zeolite thus obtained and bromoacetic acid were placed in thick-wall ampoule. Distilled water of the volume equal to that of zeolite was added and was placed in metallic capsule. Ampoule was welded, placed in metallic capsule and heated over silicone bath. Temperature was increased gradually up to $60-65^{\circ} \mathrm{C}$. Reaction duration was 6-8 hr. Then the ampoule was opened and its contents was shifted to a beaker and filtered. Remainder on a filter was washed initially by warm distilled water and then was diluted in hydrochloric acid solution and again by distilled water till neutral reaction of rinsing waters and negative reaction to bromine. The obtained cationite was dried on air and then in drying cabinet at $80^{\circ} \mathrm{C}$.

Results and analysis. At the synthesis of ionites we studied impact of various factors on the process of reaction and on static exchange capacity of the obtained cationite, considering conditions of condensation reaction of bromoacetic acid with $\mathrm{H}$-form clinoptilolite. Effect of quantity (mass.\%) of bromoacetic acid, temperature and reaction duration on the reaction progress, was studied.

Experiments showed that at the increase of bromoacetic acid quantity from 0,2 to 7 mas./h., static exchange capacity of the zeolite was increased. Results of experiments are given in figures 1- 3 . The data given in figures show that optimal ratio of zeolite and bromoacetic acid is $7: 1$. Further increase of bromoacetci acid composition doesn't lead to any significant increase in static exchange capacity of a cationite, which is limited by composition of cationes in clinoptilolite.

Study of temperature effect showed that optimal is temperature $60-65^{\circ} \mathrm{C}$. Decrease of increase of reaction temperature leads to reduction of exchange capacity.

Reaction time also affects a process of interaction of bromoacetic acid and $\mathrm{H}$-form zeolite. Optimal is reaction duration $8 \mathrm{~h}$. Further increase of reaction time doesn't exert any significant influence on cation exchange capacity.

Thus, study of the influence of various factors on the process of interaction, showed that to reach maximum index of static exchange capacity of a cationite, optimal conditions for the reaction process are: zeolite and bromoacetic acid ratio (mas.h) - 7: 1, correspondingly; reaction temperature $60-65{ }^{\circ} \mathrm{C}$, and reaction duration 8 hours.

Static exchange capacity of low-acidity cationite with carboxylic ionogen groups at the treatment in $0,1 \mathrm{~N} \mathrm{NaOH}$ water solution increase from $0,1-0,9$ (for chemically unmodified zeolite) to 5-6 mg-equiv/g.

As is seen from the obtained results, chemical modification of clinoptilolite by means of introduction of ionogen carboxyl groups into the skeleton, enables us to increase significantly their 
exchange capacity. Carboxyl groups are easily dissociated, which contributes to improvement of kinetics of exchange with various ions.

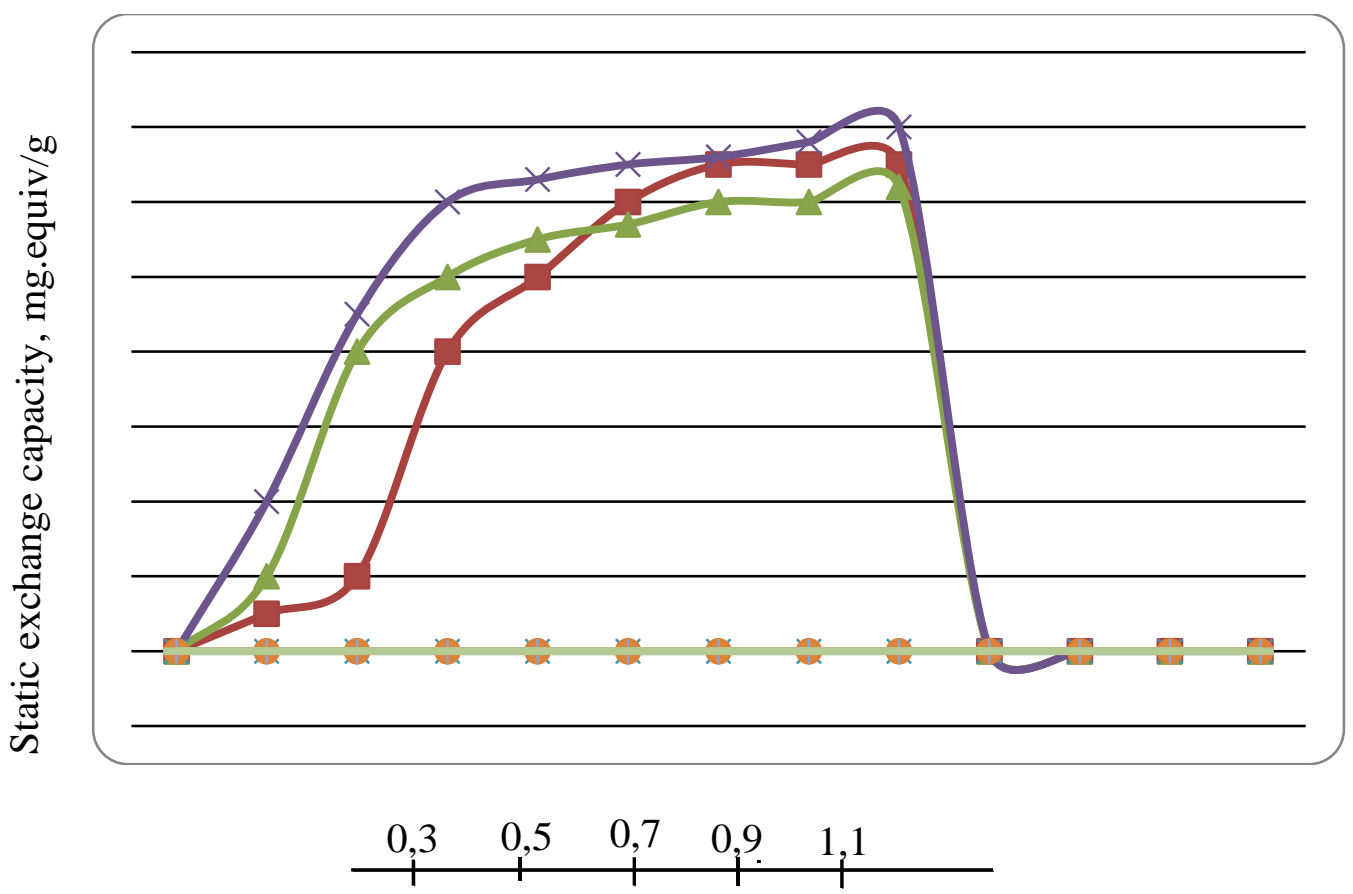

Bromoacetic acid quantity per 7 mas.hr zeolite

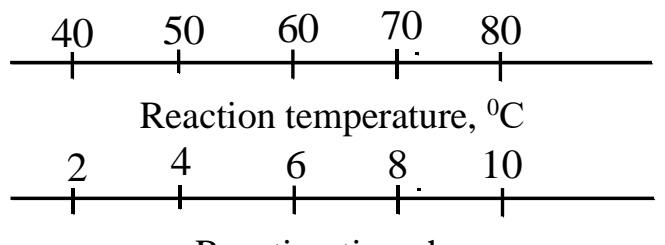

Reaction time, hr.

Fig. 1. Dependence of static exchange capacity (SEC) of cationite based on chemically modified clinoptilolite on the conditions of synthesis

-Bromoacetic acid quantity, $\mathbf{\Delta}$ - Reaction temperature, $\times$ - Reaction time

Conclusions. Synthesis of organomineral zeolite on the basis of natural sorbent - clinoptilolite type zeolite, in which sorbent is chemically bound to organic part of a molecule, containing ionogen groups - was performed. Chemical modification of clinoptilolite, by means of introduction of ionogen carboxyl groups into its skeleton, enables us to increase static exchange capacity of ionite with carboxyl ionogene groups from $0,1-0,9$ (for chemically unmodified zeolite) to 5-6 mg-equiv/g.

Low-acidity cationite with carboxyl ionogen groups in zeolite skeleton was synthesized on the basis of modified $\mathrm{H}$-form clinoptilolite and bromoacetic acid.

\section{REFERENCES}

1. D. C. Freeman, D.N. Stamires. J. Chem. Phys., 35, N 3, 799, 1961.

2. G.Sh. Papava, B.M. Mgeladze, K.P. Papava, N.S. Dokhturishvili, N.A. Maisuradze, E.Sh. Gavashelidze. Cationites on the basis of zeolites. Bulletin of Acad.Sci. GSSR, 114, № 2, 1984, p.303-306.

3. O.M. Mdivnishvili, L.V.Makharadze. Bulletin of Acad.Sci., GSSR, 65, № 2. 